\title{
La justicia en las obras de shakespeare
}

\author{
per

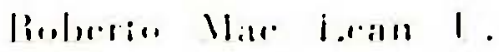

Platón hizo decir a Simónides, en "La República", que la justicia consiste en "ciar a cacia uno lo suyo, o lo que le conviene". Esta definición demostró ser tan conveniente que es muy poco lo que, descle Ulpiano hasta nuestros clias, se ha podido añadir a su precisión y equilibrio. Pero Wil!iam Shakespeare, al explicarla en términos desusados ell el foro of ta academia, descubrió perspectivas ocultos que veritió en el soneto cuarentisiete que dice:

WAis sis: 7 mirerazon csian en guarra mortal por cómo re. periire la conquista fle th miracla; mis ojos quisieran prohibir a mi ccrazón la vista cie tu imagen; mi ccrazón niega a mis ojos la legitiurdacl d'e este cirecho. Mi corazón sostiene que tu habitas an el tefeducto que nunca ha penctracio los crista-

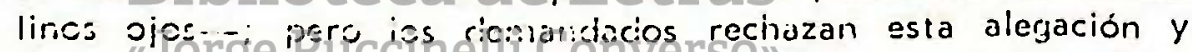
dicen "que en ellos es cionde reposa tu linda apariencia. Para clecidir este litigio se ha convocado un jurado de pensamientos, todos ârrendziarios ciel corozén; y por su veredicto sa ha determinado le porción que corresponde a ios ojos transparentes y la parte del tierno corazón. Así, pues, es deucla de mis ojes tu forma exterior, y derecho de mi corazón el intimo afecto de iu corazón".

Esta fórmula, aún vigente, traza las líneas de un ideal abstracto que se realiza en un mundo de puras formas. Cuando fue enunciada por primera vez, no había terminado el hombre de emprender el descubrimiento cle su conciencia personal, y ya tuvo que ponerla a prueba frente a una realidad bajo constantes transformaciones. "Todo cambia" habia descubierto Heráclito; y para Platón "lo suyo" o "lo que le conviene" a cada uno, dependía de la función que se cumple dentro de la República; Aristóteles lo 
hizo depender de los méritos de cada persona; y en épocas posteriores se propusieron fórmulas como "a cada uno según su capacidad", " a cada uno según su contribución" o "a cada uno según sus necesidades".

Para quien trata de averiguar la idea que tuvo Shakespeare de la Justicia, puede parecer desconcertante que por boca de Ulises 0 de Enrique IV el poeta sea partidario de la ley $y$ el orden; y por boca de Falstaff sea anarquista, y el derecho aparezca como algo extraño, ridiculo y grotesco; y aún que en labios de Timón, Tersites o el Rey Lear en su locura, sea un nihilista que desprecia la soberanía, y que profiere desengañado que aun los perros son obedecidos si se les reviste de autoridad. Pero hay que buscar la explicación cle esta aparente incongruencia en la misión que, según sus propias palabras (Hamlet, Act. III, esc. ii), corresponde al arte teatral $y$ que consiste en:

"Ofrecer un espejo a la naturaleza; mostrar a la vida sus rasgos, a la soberbia su imagen, y a la edad y cuerpo de la época su forma y apostura".

En la época en que le correspondió vivir a Shakespeare, uno de los principales acontecimientos vinculados a la idea de la justicia, en lo político y social, fue el nacimiento del Estado moderno. Durante la Edad Mediāe êl aparato coercitivo del Estado había hallado su fundamento y justificación en la ley divina. La Ciudad de

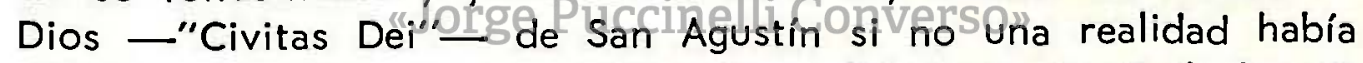
sido un arquetipo; pero movimientos políticos, como el de los gibelinos en Italia $y$, luego, una inevitable corriente de pensamiento iniciada por Maquiavelo y continuada más tarde por Bodin, lograron sustraer el gobierno temporal del Estado, del campo de acción $y$ de influencia eclesiásticos. Al no tener el Estado como origen y fundamento la palabra de Dios, era necesario encontrar una nueva razón de ser, en qué apoyar las limitaciones y deberes que impone sobre el individuo. Surgieron así los conceptos de autoridad y jerarquía, de los que luego evolucionó el de la soberanfa de las naciones. El orden y la paz quedaron establecidas como el fundamento de toda justicia; y la seguridad como el valor fundante del derecho, sin el que no pueden existir los demás valores jurídicos. Esta idea fue recogida por Shakespeare en "Troilo y Cressida" (Act. 
1, esc. iii), cuando Ulises, ante el espectáculo del ejército desmoralizado por el largo asedio a las puertas de Troya, dice:

-Quitad la jerarquia, desconcertad esa sola cuerda, y escuchad la cacofonia que se sigue... la fuerza seria el derecho, o más bien el cirechc y el delito, cntre cuya eierna querella reside la justicia: perderiun ellos sus ncmbres y la justicia el suyo. Enionces lodas las cosas se concenirarian en el poder; el poder se concentraria en la voluniad; la soluntac! en el apetito, y el apetito, lobo universal, ćcblemente secundado por la voluntad $y$ el poder haria su presa ciel universo entero".

Decir Estado, en los tiempos que vivió el poeta, equivalía casi a decir el rey. Si bien Inglaterra gozaba, desde la Carta Magna y luego después de la Guerra de las Rosas, de una posición privilegiada en este respecto, con la ascensión al trono de los Tudor, la monarquía se había fortalecido de manera considerable; $y$, en los últimos años del reinado de Isabel, se comenzó a hablar nuevamente del derecho divino que tienen los reyes a gobernar. La imagen que Shakespeare ofrece del gobernante justo -como ha anotado Christopher Morris - es que éste, por sobre todas las demás cosas, debe aceptar su responsabilidad, aunque esto signifique abandonar a Falstaff o a Cleopatra; ho debe ser traidor ni cruel, como el Rey Juan o Ricardo III; no debe usar el poder para saciar sus apetitos y lujuria, como Angelo; no debe ser un usurpador como Enrique IV, Macbeth o Claudio; no debe ser colérico y vano, como Lear, o demasiado suspicaz, como Leontes; no debe dejarse engañar por malos consejeros comolofilo, no debe anteponer su orgullo personal a su patriotismo, como Coriolano; no debe dejarse l'evar por la compasión para sí mismo, como Ricardo II; no debe dejarse guiar por ideales abstractos sin considerar los hechos, como Bruto; ni aún, como Enrique VI, llevar la santidad al extremo de la ineptitud.

Otro tema característico del pensamiento jurídico del Renacimiento es el del estado de la naturaleza, o Edad cle Oro, revivido, por Marsilio de Padua, con la doctrina del contrato social. El descubrimiento y la conquista de América habian sugerido nuevos escenarios que fueron poblados por la imaginación del hombre, de gobiernos como Utopía, Nueva Atlántida y la Ciudad del Sol. En "La Tempestad" (Act. IV) dice Próspero:

"Somos hechos de la misma tela que los sueños". 
$Y$ en la misma obra (Act. II, esc. i), otro de los personajes, el sabio consejero Gonzalo, describe su república ideal:

"En ni república dispondría de todas las cosas al revés de como so estilen. Porque no admitiría comercio alguno mi manistratura: no se conocerían las letras; nada de ricos, pobres y usos de servidumbre; nada de contratos, sucesiones, límites, áreas de tierra, cultivos, viñedos; no habría metal, trigo, vinos ni aceite; no mas ocupaciones; todos, absolutamente todos los hombies astarien ccioscs; y las mujeres también, que serian castos y puras; nada de sokeranía".

$Y$ luegro concluye:

"Todas las producciones de la naturaleza serían en ecmún, sin sudor y sin esfuerzo. La traición, la felonía, la espada, la pica, el puñal, el mosquete o cualquiera otra clase de súplica, todo quedaria suprimido, porque la naturaleza produciría por sf propia, con la mayor abundancia, lo necesario para mantener a mi inocente pueblo ..... Gobernaría con tal acierto...... que eclipsarla la Edad de Oro".

El estado de la naturaleza concebía una edad en que, como diría el Quijote a los cabreros, "no había tuyo ni mio". Pero para preservar el orden social, v satisfacer mejor las necesidades comunes, el hombre había renunciado a parte de sus derechos en favor de una autoridad superior encargada de preservar la paz y el orden. Para cumplir con sus fines esta autoridad necesitaba el respaldo de la fuerza; y comóligitesudeisuemandató,etenía los establecidos en un pacto social que reconocía cuáles derechos pasaban a la autoridad y cuáles correspondían al individuo de manera inalienable.

La dura lucha por los derechos del individuo alcanzó puntos

críticos durante la vida de Shakespeare. Desórdenes y luchas religiosas se produjeron en casi todos los países europeos. En España se persiguió a los moros y judíos, y la Inquisición inició su reinado de terror. En Francia la lucha entre católicos y calvinistas culminó en la orgía sangrienta de la noche de San Bartolomé. En Inglaterra el número de mártires católicos alcanzó una cifra elevada, y la intolerancia contra los puritanos y judíos sólo fue aplacada con las deportaciones $y$ ejecuciones que la siguieron. El derecho individual a la libertad de culto fue defendido por el filósofo Richard Hooker, quien sostuvo que sólo la tolerancia, la transigencia y la 
concordia podían ser la base de un Estado fundado en el mutuo consentimiento de sus miembros. En "El Mercader de Venecia" (Act. III, esc. i) dice Shylock, el prestamista:

"Soy un judio. ¿Es que un judio no tiene ojos? ¿Es qun un judío no tiene manos, órganos, proporciones, sentidos, afectos, pasiones? ¿Es que no está nutrido por los mismos alimentos, herido por las mismas armas, sujeto a las mismas enfermedades, curado por los mismos medios, calentado y enfriado por el mismo verano $y$ por el mismo invierno que un cristiano? ¿Si nos pinchijis, no sangramos? ¿Si nos cosquilláis, no nos reímos? ¿Si nos envenenáis, no nos morimos? iY si nos ultra. jäis, no nos vencaremos?"

Para Santo Tomás la ley de la naturaleza no sólo comprendía al hombre en su calidad racional y espiritual, sino también en la que compartía con los animales, y con las demás sustancias vivientes.

Este filósofo defendió el derecho del individuo a verse libre de la necesidad y la miseria. En Inglaterra durante la era isabelina, uno de los acontecimientos de mayor importancia había sido la transformación de la economía rural debido a la expansión del comercio de tejidos. La economia inglesa vino a depender, cada vez en mayor escala, de sus exportaciones de lana a Holanda, y como consecuencia de esto los propietarios emprendieron el cercamiento de sus heredades y de sy conversión en tierras de pastoreo. El historiador S. T. Bindoff señala como uno de los acontecimientos más importantes y trascendentales de la época, las continuas invasiones de tierras por muchedumbres empujadas por el hambre. Al escribir "Coriolano", como en sus demás obras de temas romanos, Shakespeare se inspiró en Plutarco; pero a diferencia de las demás, en esta obra se apartó del texto original y presenta como único motivo de la insurrección la escasez y carestía del trigo. Al comenzar la obra (Act. I, esc. i), dice un ciudadano:

"cuando hablo asi es porque tengo hambre de pan y no sed de venganza".

La supresión de los derechos individuales trae consigo una injusticia, pero más grave aun que la negación de la justicia es la 
arbitrariedad. La injusticia puede envolver una ley o principio que son valorizados desde un punto de vista errado, o guiados por una jerarquia diversa de valores. La arbitrariedad, en cambio, hace tábla rasa de todas las normas y reglas establecidas sin sustituirlas por otras de carácter general. Si el derecho injusto es un derecho negativo; la arbitrariedad es la negación del derecho mismo. Es la substitución de la ley por el capricho. En "El Mercader de Venecia" (Act. IV, esc. i), cuando se le propone a Porcia, en el tribunal de justicia, que haga un pequeño mal para hacer un gran bien, vislumbra la arbitrariedad futura $y$, evidenciando un respeto socrático a la ley, contesta:

"ino hay fuerza en Venecia que pueda alterar un decreto establecido; un precedente tal introduciria en el Estado numerosos abusos".

Mas no basta que se ordene dar a cada uno lo suyo, y que se respeten los derechos del individuo, ofreciéndole seguridad y certeza; la justicia debe además ser eficaz. En "Medida por Medida" (Act. II, esc. i) dice Angelo:

"No debemos hacer de la ley uno de esos espantajos que se plantan en tierra para asustar a las aves de rapiña; ni dejarla siempre en la misma actitud inmóvil, o el hábito acabará por hacer de ella su percha y no el objeto de su terror"

$Y$ también la justicia debe ser oportuna. En el conocido monólogo de Hamlet, éste enumera entre "los ultrajes y desdenes del mundo":

"las tardanzas de la justicia".

$Y$ en "Coriolano" (Act. II, esc. i), entre las críticas que se hacen a los tribunos, se les dice que:

"gastáis toda una tarde preciosa en oir un proceso entre una vendedora de naranjas y un vendedor de espitas, y luego aplazáis esta querella de tres peniques para una segunda audiencia".

Cuando a la injusticia se suman la arbitrariedad, la ineficacia de la ley, o la tardanza en su administración, el camino de la jus- 
ticia puede estar en la insurrección. En "Julio César" (Act. II, esc. i), Bruto recibe un mensaje, denunciando los abusos de César a incitándolo a rebelarse, que termina con estas palaisras:

"Habla, hiere, haz justicia!".

Uno de los primeros pensadores en justificar el derecho de insurrección ante una ley injusta fue Origenes, pacire de la Iglesia. Y Santo Tomás justificaba la rebelión cuando uria iey positiva contradecia la ley natural; siempre que la situación sea intolerable, que no se cause un daño mayor que el que se trata cle evilar y que el fin se persiga sea el bien común. En "Julio César" (Act. II, esc. i) dice Bruto en visperas de su levantamiento contra César:

"no encuentro causa personal para oporierme a él sino el bien público".

Las transformaciones politicas a consecuencia de la desmembración del Sacro Imperio y el consiguiente nacimiento de los nuevos Estados; la áparición del nacionalismo, el incremento de la navegación oceánica, y la disputa surgida con la conquista de América sobre el derecho de una nación a sojuzgar a otra, pusieron en una perspectiva más amplia el problerina de regular la conducta humana en sociedad, yorientarla hacia la realización de la justicia. Francisco de Vitoriagedesdec suecáteciraten đa Universidad de París, y Alberico Gentili, en Oxford, fueron los primeros en proponer un método para resolver sistemáticamente los nuevos problemas; método este del que evolucionó lo que más tarde se ha llamado Derecho Internacional. En la esfera de las relaciones internacionales resultaban insuficientes las soluciones aplicadas dentro de una comunidad local. En los pueblos primitivos, agrupados en tribus hordas o clanes la aparición del Derecho coincide con el establecimiento de una autoridad especializada en la aplicación de sanciones, que monopolizó la fuerza, y que gradualmente comenzó a substituir a la venganza personal o familiar. De esta manera el Derecho, y por consiguiente su aspiración a cumplir la justicia, están vinculados de modo indisoluble a la existencia de una autoridad, que puede estar representada por un jefe, un caudillo, un príncipe, o por el Estado. Este último era la suprema autoridad que conocia 
el hombre del siglo XVI, se hallaba aún en proceso de afirmación. No había nada equivalente en la vida internacional.

Era necesario, pues, volver a comenzar. Las naciones, como antes el incividuo en los pueblos primitivos, solucionaban sus conflictos tomando la justicia en sus propias manos, y siguiendo patrones de conducta que podian variar según el pueblo de que se trate. Roma habia logrado cierta uniformidad en las provincias que habia sometido, en las que imperaba la "Pax Romana"; pero desaparecida ésta era imperioso encontrar el instrumento que permitiera el desenvolvimiento normal de las relaciones entre las naciones. Se propuso la costumbre como fuente de las normas de conducta de la vida internacional; "la consuetudo" había gozado de cierto prestigio en el Derecho Romano, y fue incorporada como fuente en el "Corpus luris" de Justiniano, en diversas disposiciones del Digesto, Códices y las Institutas. Los invasores bárbaros que asolaron Europa durante la Edad Media carecieron de una ley escrita y se regian tan sólo por la costumbre. Los juristas conocidos como Giosadores, que aparecieron en Italia durante el Renacimiento habian rescatado del olvido el "Corpus luris", y adaptado muchas de las costumbres bárbaras. Pero con el Renacimiento vino también el racionalismo que comenzó a juzgar la costumbre desde un ángulo distinto. Se dijo, de una parte, que la mayoría de las costumbres eran locales en su origen y carecian de universalidad; de-otra parte muchas de las costumbres que han arraigado en la sociedad no han sido inspiradas en la concienciageneral, sino en talconveniencia e intereses de una minoría que en un momento dado ha poseido el poder suficiente para alterar el curso de los acontecimientos. En "Coriolano" (Act. III, esc. iii) se expresa un punto de vista similar:

"Si obedeciéramos en todas las cosas lo que quiere la costumbre, el polvo no barrido se amontonaría sobre el tiempo pasado, y la montaña del error se elevaría demasiado alta para que la verdad pudiese dominarla".

Otro criterio sugirió el Derecho Natural como norma reguladora del trato entre naciones.. Desde que fue formulada por primera vez por los filósofos estoicos la doctrina de la ley natural sufrió sucesivas transformaciones. Fue concebida, primero, como la ley que pone orden tanto en los seres inanimados como en los vivos, 
c como una recta razón esparcida en el universo y que no se clis. tingue esencialmente de la divinidad que gobierna al mundo. Para Ulpiano el derecho natural era un conjuntc de principios de conducta accesible únicamente al hombre como ser dotado de razón, y de la capacidad de distinguir entre el bien y el mal. Para los padres de la Iglesia, el Derecho Natural esiaba en Dios, pues "quien desconoce el verdadero Dios no puede conocer la justicia"; San Agustin dice que la ley natural es la razón y la voluntad de Dios; y Santo Tomás afirma que es una participación de la criatura racional en la ley eterna. Pero el deseo de separar los asuntos temporales de los espirituales y el racionalismo que cobraba vigor con Bacon, influyeron en la modificación de la cioctrina. La nueva noción del Derecho Natural tiene como fundamento la obligatoriedad de los pactos, y se da a conocer racionalmente para hacer posible la convivencia social. Se apoya en la doctrina del contrato social y, para explicar las relaciones internacionales, sostiene que no existe un solo contrato social sino tantos como comunidades existen en el mundo. En "Enrique $V$ ", en el parlamento en que se enumeran los reclamos del rey cle Inglaterra (Act. II, esc. iv) se cita como fundamento de éstos:

"la ley de la naturaleza y de las naciones".

Y en "Troilo Y Gressida" (Act. d', esc. ii) cuando se discute, en el palacio de Troya, la justicia de la causa que defendian en la guerra con Greciagor el fapto cle Helenas, Héctor arguye:

"Si, pues, Helena, es la mujer del rey de Esparta, como es notorio, esas leyes mordaces de la naturaleza y de las naciones proclaman muy alto que debe ser entregada a su marido".

De los acontecimientos y crisis que preocuparon a su tiempo, Shakespeare descifró para la posteridad, en palabras nutridas en la ternura humana, el difícil lenguaje de la justicia. La elaborada estructura ciel pensamiento puede deslumbrar al hombre, hechizarlo y hacerle perder contacto con su condición ligada al sufrimiento. Así la justicia puede ser árdua en su generalidad e igualdad inflexibles. Los pitágoras llegaron a hacerle perder a tal punto su conexión con el hombre que la concibieron como un número. El aforismo latino dice con sabiduría que "extrema justicia es extrema injusti- 
cia"; y Porcia, en "El Mercader de Venecia" (Act. IV, esc. i) resume este sentimiento cuando exclama:

"en extrema justicia ninguno de nosotros encontrará salvación"

La justicia no puede decir rígidamente "a todos lo mismo", sino "tratar igual casos iguales"; debe ser el compromiso entre la igualdad generalizadora y una justicia individual; debe buscar la igualdad de lo que cada hombre tiene en común con sus semejantes; pero debe respetar la desigualdad de lo que cada uno tiene como intimidad irrenunciable. Para rectificar la dureza y rigor de la justicia, Aristóteles propuso la equidad como una corrección del Derecho, como un mejoramiento de la justicia, que se viste de indulgencia para el caso concreto. Es a esta justicia entendida con altruismo, a la que se debe mucho del desarrollo jurídico de la civilización occidental. De este concepto surgió la "aequitas" del Derecho Romano que remediaba los daños causados no por un acto ilegal, sino por actos que eran demasiado legales; y la "equity" del Derecho inglés que se consideraba como una influencia humana $y$ moderadora de la ley. En "El Mercader de Venecia" (Act. IV, esc. i), en un discurso que podría ser el de Don Quijote a Sancho antes de su partida al gobierno de la ínsula, dice Porcia:

"El cetro puede mostrar bien la fuerza del poder temporal, el atributo de la majestad, y del respeto que hace temblar y temer a los reyes. Pero la clemencia está por encima de esa autoridad del cetro; tiene su trono en los corazones de los reyes; es un atributo de Dios mismo, $y$ el poder terrestre se aproxima tanto como es posible al poder de Dios cuando la clemencia atempera la justicia".

$Y$ es que Shakespeare concibe la justicia, antes que nada, como esperanza del hombre, y como la afirmación —en las palabras de Hamlet- que hay más entre el cielo y la tierra "de lo que sueña nuestra filosofía". 